\title{
Secretory phospholipase A2-X (Pla2g10) is a novel progesterone receptor target gene exclusively induced in uterine luminal epithelium for uterine receptivity in mice
}

Hee Kyoung Park ${ }^{1,3}$, So Hee Park', Miji Lee ${ }^{1}$, Gyeong Ryeong Kim', Mira Park', Seung Chel Yang ${ }^{1}$, Yeon Sun Kim ${ }^{1}$, Hyunjung J. Lim², Hye-Ryun Kim" ${ }^{1 *}$ and Haengseok Song ${ }^{1 *}$ (D)

\begin{abstract}
Background: Aberration of estrogen $\left(E_{2}\right)$ and/or progesterone $\left(\mathrm{P}_{4}\right)$ signaling pathways affects expression of their target genes, which may lead to failure of embryo implantation and following pregnancy. Although many target genes of progesterone receptors (PRs) have been identified in uterine stroma, only a few PR targets have been reported in the epithelium. Secretory phospholipase $A_{2}-\left(P L A_{2}\right)-X$, a member of the $P L A_{2}$ family that releases arachidonic acids for the synthesis of prostaglandins that are important for embryo implantation, is dysregulated in the endometrium of patients suffering from repeated implantation failure. However, it is not clear whether $S P L A_{2}-X$ is directly regulated by ovarian steroid hormones for embryo implantation in the uterus.

Result: $P_{4}$ induced the Pla2g10 encoding of secretory $P L A_{2}-X$ in the apical region of uterine $L E$ of ovariectomized mice via PR in both time- and dose-dependent manners, whereas $E_{2}$ significantly inhibited it. This finding is consistent with the higher expression of Pla2g10 at the diestrus stage, when $\mathrm{P}_{4}$ is elevated during the estrous cycle, and at $\mathrm{P}_{4}$-treated delayed implantation. The level of Pla2g10 on day 4 of pregnancy (day 4) was dramatically decreased on day 5, when PRs are absent in the LE. Luciferase assays of mutagenesis in uterine epithelial cells demonstrated that four putative PR response elements in a Pla2g10 promoter region are transcriptionally active for Pla2g10. Intrauterine delivery of small interfering RNA for Pla2g10 on day 3 significantly reduced the number of implantation sites, reinforcing the critical function(s) of Pla2g10 for uterine receptivity in mice.
\end{abstract}

Conclusions: Pla2g10 is a novel PR target gene whose expression is exclusively localized in the apical region of the uterine LE for uterine receptivity for embryo implantation in mice.

Keywords: Pla2g10, Progesterone receptor, Uterine epithelium, Uterine receptivity, Embryo implantation

*Correspondence: hrkim@cha.ac.kr; hssong@cha.ac.kr

†Hee Kyoung Park and So Hee Park contributed equally to this work

1 Department of Biomedical Science, CHA University, Gyeonggi-do, Seongnam-si 13488, Republic of Korea

Full list of author information is available at the end of the article

\section{Background}

It is well understood that prostaglandins (PGs) are critical for sequential events of female reproduction from ovulation to parturition [1-3]. PGs are generated from arachidonic acid (AA) by phospholipase $\mathrm{A}_{2} \mathrm{~s}\left(\mathrm{PLA}_{2} \mathrm{~s}\right)$ followed by cyclooxygenases. PLA $A_{2}$ enzymes are classified into two groups, cytosolic and secretory. Cytosolic $\mathrm{PLA}_{2} \mathrm{~s}\left(\mathrm{CPLA}_{2} \mathrm{~s}\right)$, which are regulated by $\mathrm{Ca}^{2+}$-dependent

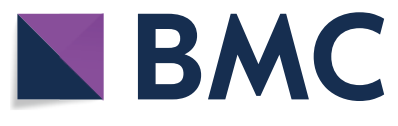

(c) The Author(s) 2020. This article is licensed under a Creative Commons Attribution 4.0 International License, which permits use, sharing, adaptation, distribution and reproduction in any medium or format, as long as you give appropriate credit to the original author(s) and the source, provide a link to the Creative Commons licence, and indicate if changes were made. The images or other third party material in this article are included in the article's Creative Commons licence, unless indicated otherwise in a credit line to the material. If material is not included in the article's Creative Commons licence and your intended use is not permitted by statutory regulation or exceeds the permitted use, you will need to obtain permission directly from the copyright holder. To view a copy of this licence, visit http://creativeco mmons.org/licenses/by/4.0/. The Creative Commons Public Domain Dedication waiver (http://creativecommons.org/publicdomain/ zero/1.0/) applies to the data made available in this article, unless otherwise stated in a credit line to the data. 
translocation and phosphorylation, have a preference for $\mathrm{AA}$ in membrane phospholipids and play an essential role in agonist-induced AA release. The $\mathrm{CPLA}_{2} \alpha$-derived $\mathrm{AA}$ is important for the PG synthesis that is required for on-time implantation [1]. Several secretory $\mathrm{PLA}_{2} \mathrm{~S}$ $\left(\mathrm{sPLA}_{2} \mathrm{~s}\right)$, including groups IIA, III, V, and $\mathrm{X}$, are likely to be involved in AA release and subsequent eicosanoid production during inflammatory conditions [4]. Several sPLA $_{2} \mathrm{~s}$, as well as $\mathrm{CPLA} \mathrm{A}_{2} \mathrm{~s} \alpha$, are spatiotemporally induced in mouse uterus for uterine receptivity [1]. It was previously reported that PLA2G10 encoding of $\mathrm{sPLA}_{2}-\mathrm{X}$ is dysregulated in the endometrium of patients with repeated implantation failure (RIF) [5]. However, detailed mechanism(s) by which ovarian steroid hormones regulate expression of Pla2g10 in the uterus remain unanswered.

Ovarian steroid hormones, estrogen $\left(E_{2}\right)$ and progesterone $\left(\mathrm{P}_{4}\right)$, orchestrate dynamic changes in the uterus during reproductive cycles [6-8]. These hormones act on uterine physiology mainly via their own nuclear receptors; namely, estrogen receptors and progesterone receptors (PRs), respectively $[9,10]$. Sophisticated actions of these hormones on major uterine cell types, including various immune cells, are prerequisites for changing the uterine environment from the pre-receptive to the receptive phase for successful embryo implantation [11-13]. Desynchronized actions of these hormones may provide various causes of RIF. $\mathrm{P}_{4}$ play critical roles for the establishment and maintenance of pregnancy by not only its endocrine but also immunological effects [14-16]. $\mathrm{P}_{4}-$ PR transcriptional network along with estrogen signaling promotes spatiotemporal regulation of various target genes for achieving uterine receptivity in the uterus [17]. Whereas most of the PR target genes are expressed in stromal cells, several genes including Amphiregulin (Areg), Indian hedgehog (Ihh), Calcitonin $(C t)$, GATA binding protein 2 (Gata2), and sex-determining region Y-related high-mobility group box 17 (Sox17) have been identified in the uterine epithelium to date [18-22]. Here we demonstrate that Pla2g10, one of dysregulated genes in the endometrium of patients with RIF, is a novel PR target gene that is exclusively induced in uterine luminal epithelium (LE) for uterine receptivity for embryo implantation in mice.

\section{Results}

PLA2G10 dysregulated in human endometrium of patients with RIF is regulated by $P_{4}$

Previously, we demonstrated that a group of genes, including PLA2G10, is dysregulated in the endometrium of patients with RIF [5]. Volcano plots and realtime reverse transcriptase-polymerase chain reaction (RT-PCR) for endometrial samples demonstrate that
PLA2G10 mRNAs were significantly down-regulated in the endometrium of patients with RIF at mid-luteal phase (Fig. 1a, b). To further investigate the underlying mechanism of dysregulated expression of PLA2G10 in the endometrium of patients with RIF, we examined steroid hormonal regulation of Pla2g10 in mouse uterus. Because $\mathrm{P}_{4}$ is an essential steroid hormone to prepare embryo implantation in the uterus, it was first examined whether Pla2g10 expression is regulated in the uterus by $\mathrm{P}_{4}$ using an ovariectomized (OVX) mouse model. $\mathrm{P}_{4}$ was given to OVX mice whose uteri were collected at different time points $(0,3,6$, and $24 \mathrm{~h})$ after hormone treatment (Fig. 1c, d). The RT-PCR and real-time RT-PCR results demonstrate that Pla2g10 expression was gradually increased by $\mathrm{P}_{4}$ in a time-dependent manner, with the highest level at $24 \mathrm{~h}$ (Fig. 1d). Immunofluorescence staining shows that PLA2G10 is mainly localized in the apical region of LE cells in mouse uterus (Fig. 1c). These results suggest that $P l a 2 g 10$ may be a novel $\mathrm{P}_{4}$ target gene that is exclusively induced in the LE of the uterus.

\section{$\mathrm{E}_{2}$ inhibits both basal and $\mathrm{P}_{4}$-dependent expression of Pla2g10 in mouse uterus in a time-dependent manner}

To investigate the effects of $\mathrm{E}_{2}$ on Pla2g10 expression in mouse uterus, $E_{2}$ with or without $\mathrm{P}_{4}$ was given to OVX mice whose uteri were collected at different time points after hormone treatment(s). A single injection of $E_{2}$ significantly reduced basal levels of Pla2g10 mRNAs in mouse uterus of OVX mice (Fig. 1e). Furthermore, $E_{2}$ suppressed $\mathrm{P}_{4}$-dependent induction of Pla2g10 at 3 and $6 \mathrm{~h}$ after hormone treatments, whereas the inhibitory action was no longer effective at $24 \mathrm{~h}$ (Fig. 1f). These results suggest that $E_{2}$ has inhibitory actions on basal and $\mathrm{P}_{4}$-dependent expression of Pla2g10 in mouse uterus.

\section{$\mathrm{P}_{4}$ regulates $\mathrm{Pla2g} 10$ induction via its nuclear $P R$ in a dose-dependent manner}

To investigate whether Pla2g10 expression is regulated by $\mathrm{P}_{4}$ in a dose-dependent manner, various concentrations $(0.25-2 \mathrm{mg})$ of $\mathrm{P}_{4}$ were given to OVX mice and Pla2g10 expression was evaluated $24 \mathrm{~h}$ after $\mathrm{P}_{4}$ injection. RT-PCR and real-time RT-PCR analyses show Pla2g10 induction by $\mathrm{P}_{4}$ in a dose-dependent manner, with a peak level in uterine samples with $2 \mathrm{mg}$ (Fig. 2a). To determine whether $\mathrm{P}_{4}$-induced Pla2g10 expression is mediated via nuclear PRs in mouse uterus, OVX mice were pretreated with a PR antagonist RU-486 30 min before $\mathrm{P}_{4}$ injection. RU-486 pretreatment significantly abrogated $\mathrm{P}_{4}$-dependent induction of Pla2g10 as well as Areg, a known $\mathrm{P}_{4}$ target gene expressed in the LE of mouse uterus. These results suggest that $\mathrm{P}_{4}$-dependent induction of Pla2g10 expression works through nuclear PR in the uterus (Fig. 2b, c). 


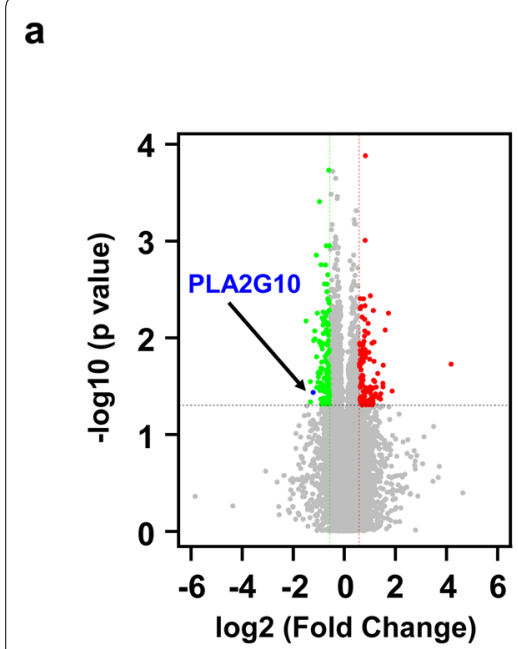

b

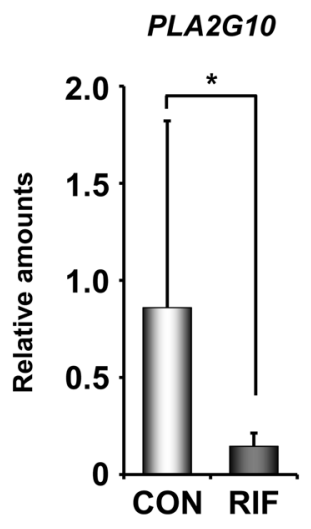

e
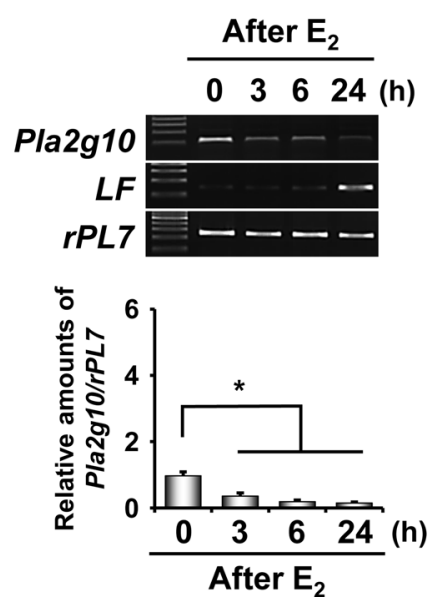

C

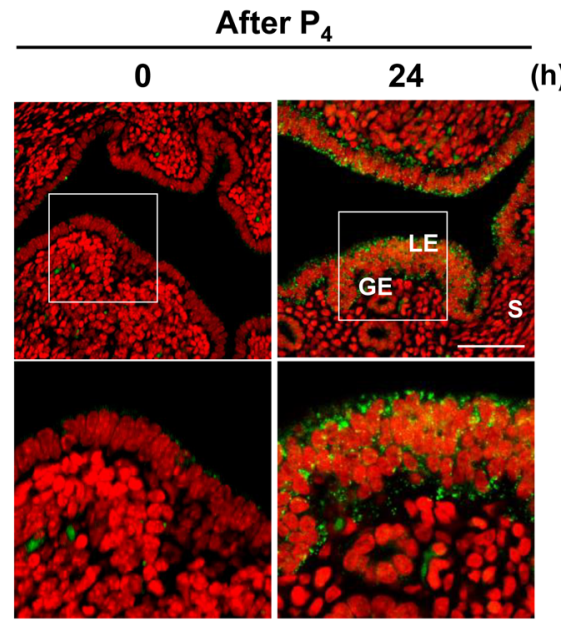

f
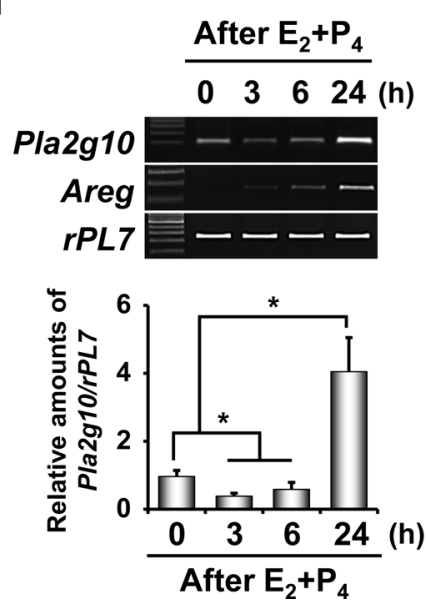

Fig. 1 Pla2g10 expression is positively regulated by $\mathrm{P}_{4}$ in the uterus. a A volcano plot to compare expression profiles of the mid-luteal phase endometria from the healthy women $(C O N, n=6)$ vs patients with RIF $(n=9)$. PLA2G10 is visualized as one of downregulated genes in the endometria of patients with RIF. $\mathbf{b}$ Real-time RT-PCR analysis for relative mRNA levels of PLA2G10 between endometria of CON and patients with RIF in mid-luteal phase. c Immunofluorescence of PLA2G10 $24 \mathrm{~h}$ after $\mathrm{P}_{4}$ treatment in uteri of OVX mice. The bottom panels show higher magnification images of the boxed area. Green and red colors indicate the presence of PLA2G10 and nuclei, respectively. LE, luminal epithelium; GE, glandular epithelium; S, stroma. Scale bar: $50 \mu \mathrm{m}$. d-f RT-PCR and real-time RT-PCR results to analyze relative levels of Pla2g10 mRNA by $\mathbf{d} \mathrm{P}_{4}$ ( $2 \mathrm{mg} / \mathrm{mouse}$ ), e $E_{2}\left(200 \mathrm{ng} /\right.$ mouse), and $\mathbf{f} E_{2}+P_{4}$ treatment in uteri of OVX mice at different time points ( $n=4-5$ mice for each time point). Expression levels of Areg and $L F$ mRNAs were also evaluated to validate appropriate $P_{4}$ and $E_{2}$ hormone responses in $O V X$ mice used in this experiment, respectively. ${ }^{*} p<0.05$

\section{Expression of Pla2g10 is elevated in $\mathrm{P}_{4}$-dominant diestrus} stage during estrous cycle

To further understand $\mathrm{P}_{4}$-dependent regulation of Pla2g10 in the uterus, we examined its expression in the uterus at different stages of the estrous cycle during which the uterus undergoes cyclic hormonal changes. Consistent with hormone-dependent profiles of Pla2g10 expression, it was notably expressed in the diestrus stage when $\mathrm{P}_{4}$ is dominant, but not in the proestrus and estrus stages when levels of $E_{2}$ are high (Fig. 2d, e). Accordingly, PLA2G10 was mainly detected in the LE of mouse uterus in the diestrus stage (Fig. 2e).
Pla2g10 expression coincides with PR in the LE for uterine receptivity for embryo implantation

During early pregnancy in mice, the uterus is influenced by $\mathrm{P}_{4}$ from newly formed corpus lutea from day 3 of pregnancy (day 3) onwards [6]. Thus, we examined expression patterns of Pla2g10 in mouse uterus during early pregnancy. Pla $2 g 10$ was highly expressed on days 3 and 4, whereas it remained at basal levels on days 1 and 2 when $\mathrm{E}_{2}$ was dominant (Fig. 3a). Interestingly, $\mathrm{P}_{4}$-dependent expression of Pla2g10 was significantly reduced in both implantation site (IS) and inter-IS on day 5 (Fig. 3b). Similar observation was made in the 


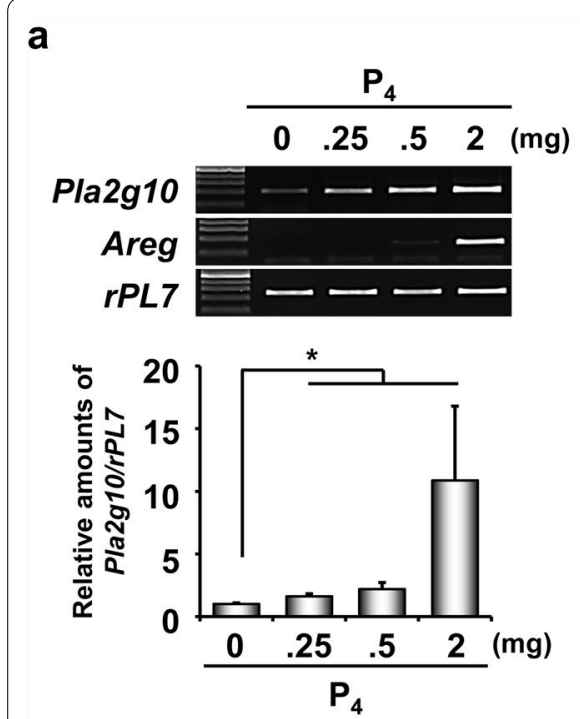

b
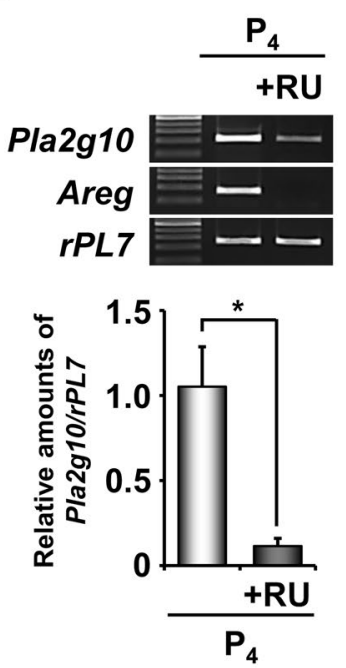

C

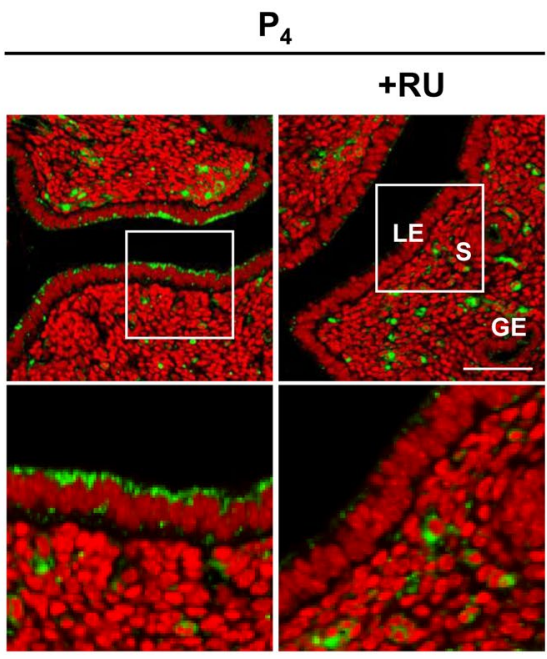

d
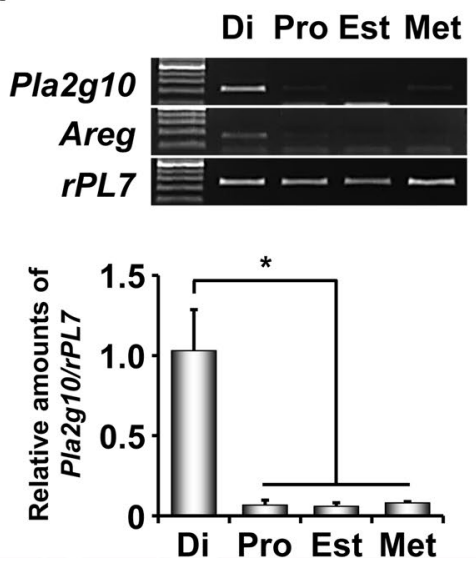

e
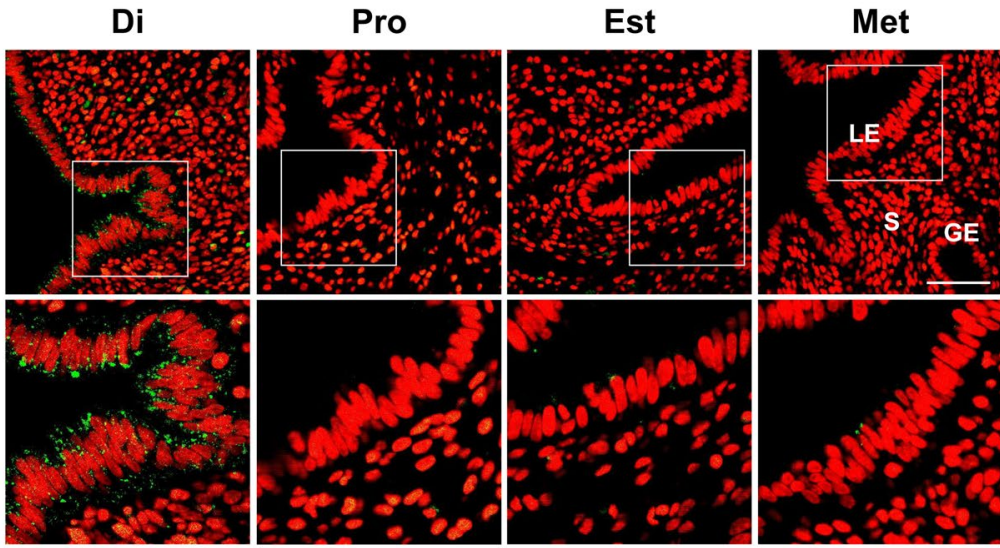

Fig. $2 \mathrm{P}_{4}$-dependent induction of Pla2g10 is mediated via its nuclear receptor, PR, during estrous cycle in the uterus. a Analyses of expression levels of Pla2g10 mRNAs in mouse uterus exposed to various concentrations of $\mathrm{P}_{4}(0.25-2 \mathrm{mg})$. $\mathbf{b}$-c Evaluation of the inhibitory action of PR antagonist, RU-486 (1 mg/mouse) on $\mathrm{P}_{4}$ (2 mg/mouse)-induced Pla2g10 expression in uteri of OVX mice ( $\mathrm{n}=5$ per each group) by $\mathbf{b}$ RT-PCR and real-time RT-PCR and $\mathbf{c}$ immunofluorescence. The bottom panels show higher magnification images of the boxed area. $\mathbf{d}$ Analyses of expression levels of Pla2g10 mRNAs during estrous cycle. e Immunofluorescence of PLA2G10 in the uterus during estrous cycle. The bottom panels show higher magnification images of the boxed area. Green and red colors indicate the presence of PLA2G10 and nuclei, respectively. RU RU-486, LE luminal epithelium, GE glandular epithelium, S stroma, Di diestrus, Pro proestrus, Est estrus, Met metestrus. Scale bar: $50 \mu \mathrm{m} .{ }^{*} \mathrm{p}<0.05$

uterus on days 4 and 5 of pseudopregnancy (data not shown). Considering that $\mathrm{P}_{4}$ levels are similarly maintained on days 4 and 5 [23, 24], downregulation of PLA2G10 in the LE on day 5 may be associated with loss of PR in this compartment. In fact, it is interesting to observe that PR as well as and PLA2G10 is dramatically reduced in the LE irrespective of the implanting blastocyst on day 5 (Fig. 3b) and day 5 of pseudopregnancy (data not shown).
Pla2g 10 is regulated by $\mathrm{P}_{4}$-PR-dependent signaling in mouse uterus during delayed implantation

To further evaluate whether the sudden decrease of the PLA2G10 expression in the LE on day 5 is caused by loss of PR, we used an experimentally-induced delayed implantation model (DIM) in mice (Fig. 3c). PLA2G10 expression was maintained in a $\mathrm{P}_{4}$-primed uterus at a state of dormancy $\left(\mathrm{P}_{4} 24 \mathrm{~h}\right)$. However, $24 \mathrm{~h}$ after termination of delayed implantation with an injection of $E_{2}$ 

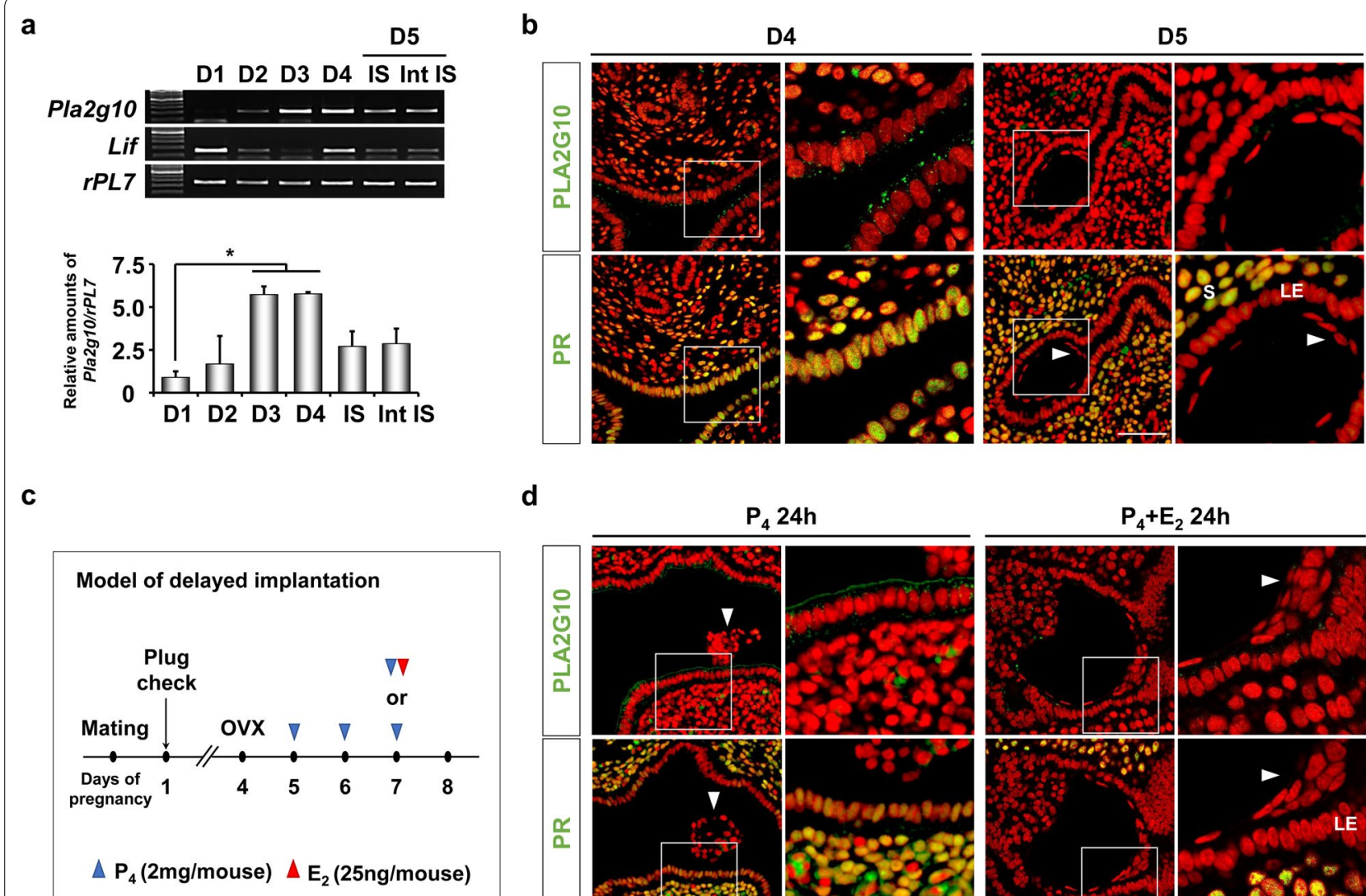

d
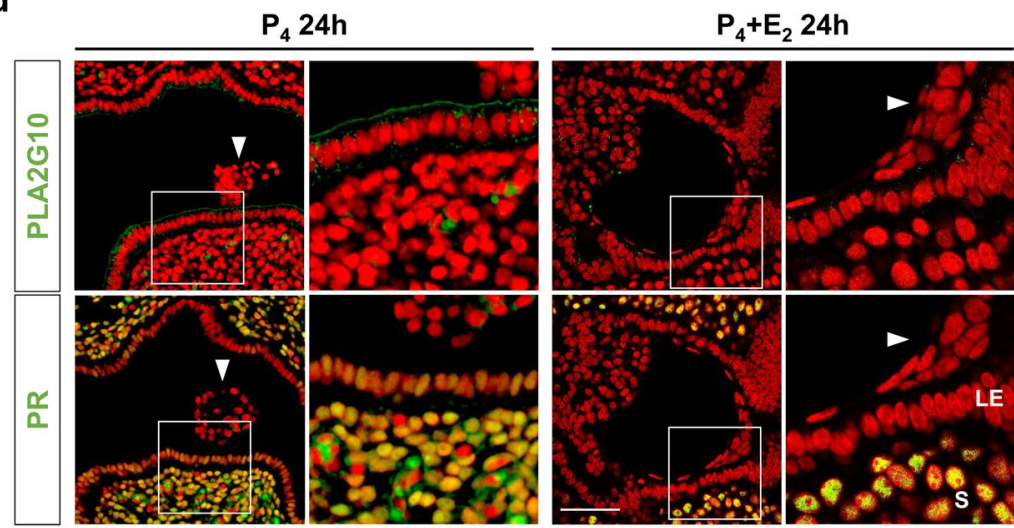

Fig. 3 PR-dependent Pla2g10 expression in the uterus during early pregnancy and a delayed implantation model. a RT-PCR and real-time RT-PCR analyses to monitor the relative levels of Pla2g10 mRNAs in the uterus on days 1 to 5 of pregnancy (D1-D5). IS implantation site, int IS inter IS. b Immunofluorescence of PLA2G10 and PR in uteri on D4 and D5. c A schematic diagram to show the experimental schedule to experimentally-induced delayed implantation. $\mathbf{d}$ Immunofluorescence of PLA2G10 and PR in uteri on the delayed implantation model. The right panels show higher magnification images of the boxed area. Green and red colors indicate the presence of PLA2G10 or PR and nuclei, respectively. Arrowheads indicate the location of implanted blastocyst. LE luminal epithelium, S stroma. Scale bar: $50 \mu \mathrm{m}$

$\left(\mathrm{P}_{4}+\mathrm{E}_{2} 24 \mathrm{~h}\right)$, it disappeared in the LE in mouse uterus (Fig. 3d). The loss of PLA2G10 in the LE at $\mathrm{P}_{4}+\mathrm{E}_{2} 24 \mathrm{~h}$ coincided with loss of PR in the LE during DIM. Taken together, these results suggest that PLA2G10 expression exclusively depends on PR in mouse uterus during early pregnancy and DIM.

\section{Pla2g10 promoter has functional PREs}

To further understand the molecular mechanism(s) by which the $\mathrm{P}_{4}$-PR signaling pathway regulates Pla2g10 expression at transcriptional levels, a series of luciferase assays with a proximal promoter region of Pla2g10 gene containing putative PR response elements (PREs) was performed in Ishikawa cells, human endometrial adenocarcinoma cells. In silico analyses via a PROMO program (http://alggen.lsi.upc.es) suggest that four putative PREs were found in $-840 /+65$ of the Pla2g10 promoter. These PREs were also validated by ChIP-seq analyses in a previous study [25]. The luciferase activity of the Pla2g10 promoter was significantly increased when cotransfected with PRA or PRB expression vector along with $\mathrm{P}_{4}$ (Fig. 4a). To determine which PRE is functionally critical for PR-dependent Pla2g10 transcription, four putative PREs in the Pla2g10 proximal promoter region $(-840 /+65)$ were mutated (Fig. 4b). All four mutations (mt) at $-801 /-793,-356 /-350,-310 /-304$, and $-290 /-284$ PREs at the Pla2g10 promoter showed about $40 \%$ reduced luciferase activity when co-transfected with PR(s) (Fig. 4c). These results indicate that Pla2g10 transcription is directly regulated by $\mathrm{PR}$ in the uterus.

In vivo delivery of siRNA to knock-down Pla2g10 disturbs embryo implantation

We next performed in vivo interference of Pla2g10 to investigate whether Pla2g10 contributes to embryo implantation in mouse uterus. Intrauterine injection of siRNA against Pla2g10 (siPla2g10) (100 pmol per 
a

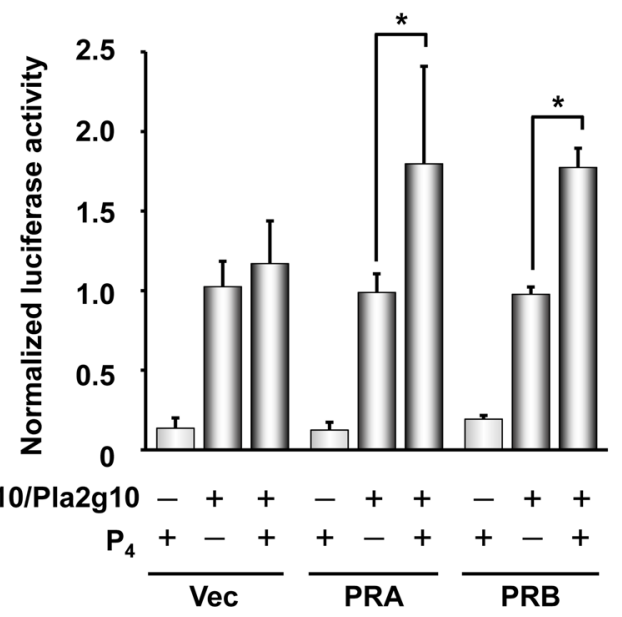

b

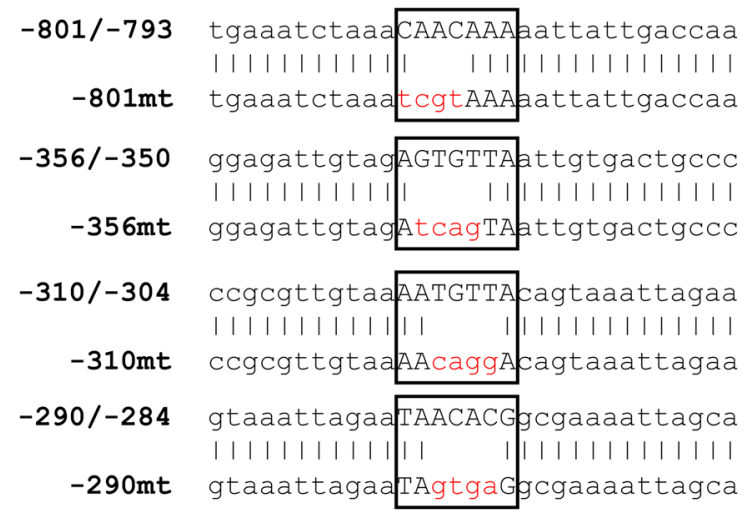

C

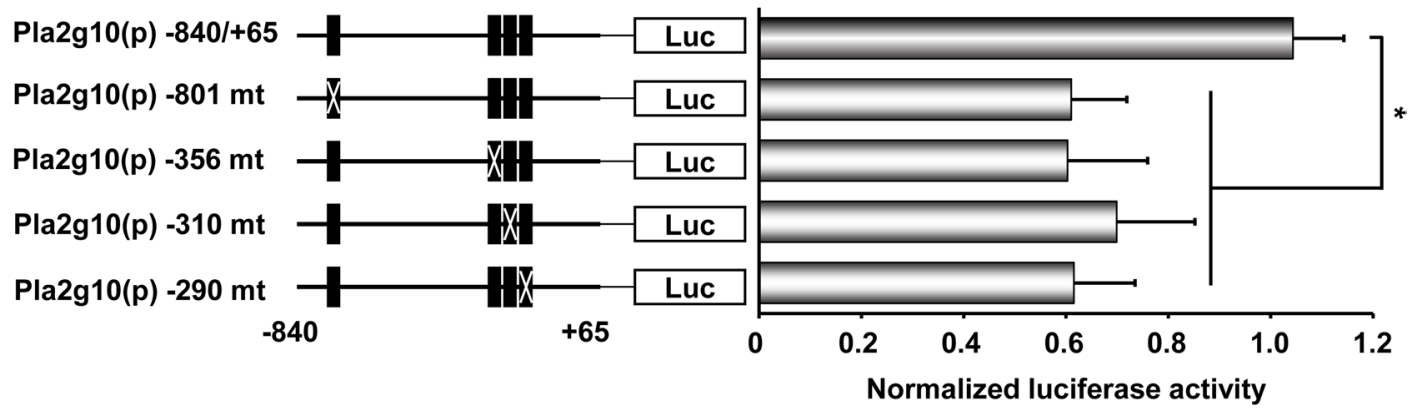

Fig. 4 Pla2g10 promoter has functional PREs in uterine epithelial cells. a Luciferase assays for a proximal region of Pla2g10 promoter in Ishikawa cells where control (Vec), PRA, or PRB vectors were co-transfected with $\mathrm{pGL4.10/Pla2g10} \mathrm{luciferase} \mathrm{vector} \mathrm{under} 1 \mu \mathrm{M} \mathrm{P}_{4}$. Vec: empty vector. b A schematic cartoon to show Pla2g10 promoter that contains putative PREs that were mutated by site-directed mutagenesis. Box, PRE sequence. Red letter, mutated sequence. $\mathbf{c}$ Luciferase assays for Pla2g10 promoter constructs with a mutation ( $\mathrm{mt}$ ) on each PRE in Ishikawa cells under the same conditions as $\mathbf{a}$. The normalized luciferase activities are shown by ratio to renilla activity. Data are presented as the mean \pm SD of three independent experiments. ${ }^{*} p<0.05$

uterine horn) on day 3 caused significant knock-down of PLA2G10 expression on day 4 (Fig. 5a). In vivo interference of Pla2g10 expression with siPla2g10 in mouse uterus significantly decreased the number of IS on day 6 (6.5 vs 2.5) compared to the control horns with negative control siRNA (siNC) (Fig. 5b, c). However, a few embryos successfully implanted in mouse uterus with siPla2g10. Gross histology and ALP staining for IS on day 6 showed that implantation normally occurs in the uterus with siPla2g10 (Fig. 5d). Furthermore, ARG2 localization in the decidualizing stromal cells surrounding the implanted embryo on day 6 was similarly observed between uteri with siPla2g10 and siNC (Fig. 5e), suggesting that the uterine environment could be locally disturbed, but not systemically altered in mouse uterus by siPla2g10. Collectively, these results suggest that $\mathrm{P}_{4}$-PR signaling induces expression of Pla2g10 in LE, which participates in PG biosynthesis critical for uterine receptivity for embryo implantation in mice (Fig. 6).

\section{Discussion}

Pla2g10 is known as a $\mathrm{Ca}^{2+}$-dependent low molecularweight enzyme (13-18 $\mathrm{kDa})$ that is involved in biosynthesis of PGs, an important lipid mediator for embryo implantation [26, 27]. We previously demonstrated that mice deficient of Pla2g4a, a cytosolic form of PLA have aberrant uterine spacing of embryos and deferred embryo implantation. The deferred implantation and fetal growth restriction in Pla2g4a deficient mice were significantly recovered by exogenous PG administration [1]. Subsequent studies have supported this notion that $\mathrm{PLA}_{2} \mathrm{~S}$-derived AA is important for PG synthesis that is crucial for on-time implantation [28-30]. In our previous study, PLA2G10 was identified as a dysregulated gene in 




microarray analyses in the endometrium of patients with RIF in whom $\mathrm{P}_{4}$ signaling could be locally impaired [5]. In fact, Pla2g10 expression was gradually increased by $\mathrm{P}_{4}$ in a dose-dependent manner (Fig. 1). In line with this result, a recent study shows that the role of $\mathrm{PLA}_{2} \mathrm{~S}$ in acrosome reaction in vitro depends on $\mathrm{P}_{4}$ concentration [31]. In this study, we clearly demonstrate that Pla2g10 is a novel $\mathrm{PR}$ target gene whose expression is exclusively induced in the LE in mouse uterus.

Molecular cross-talks between the blastocyst and the uterus induce growth factors, adhesion molecules, cytokines, and transcription factors to prepare uterine conditions for embryo implantation [6, 32-35]. $\mathrm{P}_{4}-\mathrm{PR}$ target gene networks are known to have critical functions for embryo implantation [8, 36, 37]. Most of PR target genes, such as Hoxa10 and Hand2, are expressed in stromal cells $[8,17]$. Only several PR target genes, such as Areg, Ihh, CT, Gata2, and Sox 17 have been identified in the epithelial compartment [18-22]. Areg is a wellknown PR target gene whose expression is increased in the uterine epithelium in response to $\mathrm{P}_{4}$ for uterine receptivity. With the onset of blastocyst attachment late on day 4, Areg mRNA accumulated in the LE exclusively at the sites of blastocysts [18], which may compensate for the deficiency of HB-EGF around the time of embryo implantation in the uterus of HB-EGF knockout mice [38]. Very high levels of $I h h$ mRNA are seen in the luminal and glandular epithelia on day 3 for preparing embryo implantation [19]. Consistent with these results, Pla2g10 is expressed in LE during the early pregnancy 


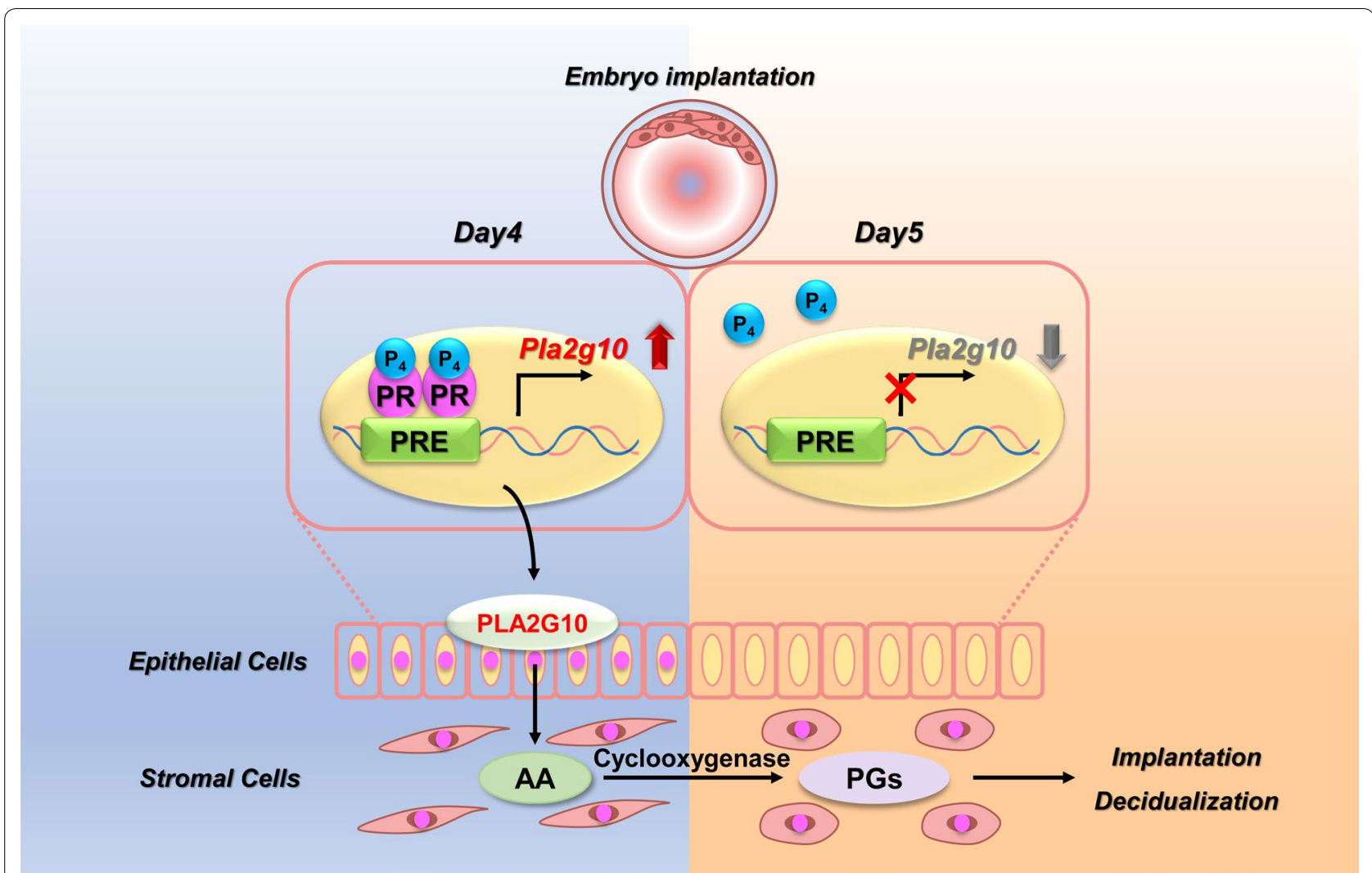

Fig. 6 A schematic cartoon to describe the molecular mechanism by which $\mathrm{P}_{4}-\mathrm{PR}$ regulates Pla2g10 expression for uterine receptivity for embryo implantation in the luminal epithelium in mouse uterus

(Fig. 3). $\mathrm{P}_{4}$ promotes expression of not only Pla2g10, a $\mathrm{Ca}^{2+}$-dependent enzyme, but also $\mathrm{CT}$ in uterine epithelium [20, 39]. Interestingly, CT leads to increased concentration of intracellular $\mathrm{Ca}^{2+}$, suggesting that the $\mathrm{P}_{4}-\mathrm{PR}$ signaling, probably via $\mathrm{CT}$ induction, could regulate Pla2g10 expression and functional activities for uterine receptivity for embryo implantation [20, 40]. Gata2, a $\mathrm{P}_{4}$ target gene, is colocalized in the uterine epithelium during early pregnancy with $\mathrm{PR}$, and promotes expression of Pgr gene but also regulates downstream progesterone responsive genes, such as Sox17, in conjunction with the PR [21, 22, 41]. We also found three putative GATA binding sites in nearby $-801 /-793$ PRE of the Pla2g10 promoter (data not shown). Thus, it is suggested that Pla2g10 expression could be regulated in the uterine epithelium via PR-GATA2 dependent manner.

It is well-known that stromal PR is the major regulator of the expression of $\mathrm{P}_{4}$ target genes and the ability of $\mathrm{P}_{4}$ to inhibit $\mathrm{E}_{2}$-induced epithelial cell proliferation [42]. However, a recent study shows that epithelial PR acts to inhibit $E_{2}$-induced epithelial proliferation and is essential for uterine development and function, suggesting the importance of epithelial PR for embryo implantation [43]. During early pregnancy, PR is transiently expressed in the epithelium just prior to embryo implantation [43, 44]. After embryo implantation occurs, PR expression in the epithelium rapidly decreases [44] whereas its expression in uterine stroma increases and persists throughout decidualization in mice [45]. Loss of PR expression in the uterine epithelium is crucial for luminal closure for embryo implantation [46]. A previous report suggests that $E_{2}$ down-regulates $P R$ in uterine epithelium through paracrine actions mediated by stromal ER $\alpha$ [47]. This could support the notion that a rapid decrease of $\mathrm{P}_{4}$-dependent Pla2g10 expression in the epithelium in mouse uterus may be caused by reduction of epithelial PR (Fig. 3b). In fact, we found that expression of $\mathrm{P}_{4}$-dependent Pla2g10 was suppressed by $\mathrm{E}_{2}$ in uteri of OVX mice (Fig. 1f). This notion is supported by the results that Pla2g10 promoter has functional PREs (Fig. 4c) and expression of PLA2G10 is synchronized with that of PR in epithelial cells during early pregnancy (Fig. 3a, b). Although Areg is specifically induced in uterine epithelium surrounding the implanting blastocyst on day 5 , Pla2g10 is not influenced by the presence of implanting blastocyst (Fig. 3b, d). This suggests that the 
molecular mechanism by which $\mathrm{P}_{4}-\mathrm{PR}$ signaling regulates Pla2g10 expression seems to be different from other PR target genes expressed in the epithelium in the mouse uterus during embryo implantation. Intrauterine delivery of siRNA has been performed to elucidate the function of genes on embryo implantation in mice [48-50]. In general, the in vivo action of delivered siRNAs partially inhibits expression levels of target genes and reduces the number of IS at the time of embryo implantation. Figure 5 shows similar results that intrauterine delivery of siRNA for Pla2g10 inhibited PLA2G10 expression in LE on day 4 and reduced the number of IS on day 6 .

\section{Conclusion}

Collectively, this is the first report that Pla2g10 is a novel $\mathrm{P}_{4}$-PR target gene that is exclusively induced in LE to prepare uterine receptivity for embryo implantation in mice (Fig. 6). Further studies are needed to comprehensively understand molecular regulation of steroid hormone receptors on transcriptional activity of the Pla2g10 promoter.

\section{Methods}

\section{Animals}

All animals were maintained and handled according to the policies approved by CHA University Institutional Animal Care and Use Committee (IACUC, approval number 170002). Eight-week-old adult ICR mice were provided by Orient Bio, Inc (Gapyeong, Gyeonggi, Korea).

\section{Hormone treatments}

To examine the actions of ovarian steroid hormones on expression of Pla2g10, adult female mice were OVX, rested for 14 days, and then appropriately treated with steroid hormones for each experiment performed in this study. Mice were sacrificed and their uterine horns were collected for real-time RT-PCR and/or immunofluorescence after ovarian steroid hormone treatment.

To investigate time-dependent actions of $\mathrm{P}_{4}$ (SigmaAldrich, USA) and $E_{2}$ (17 $\beta$-estradiol, Sigma-Aldrich) on the expression of Pla2g10 in mouse uterus, adult OVX mice were subcutaneously injected with $\mathrm{P}_{4}(2 \mathrm{mg} /$ mouse $)$ or $\mathrm{P}_{4}+\mathrm{E}_{2}(200 \mathrm{ng} / \mathrm{mouse})$ and sacrificed at various time points $(0,3,6$, and $24 \mathrm{~h})$ after injection. To examine the dose-dependent induction of Pla2g10 by $\mathrm{P}_{4}$, mice were given a single injection of vehicle (sesame oil, $0.1 \mathrm{ml} /$ mouse) or $\mathrm{P}_{4}$ at various concentrations $(0.25-2 \mathrm{mg})$. To analyze whether $\mathrm{P}_{4}$ works through a nuclear PR for Pla2g10 expression in mouse uterus, adult OVX mice were pretreated with the PR antagonist RU-486 $(1 \mathrm{mg} /$ mouse, Sigma-Aldrich), $30 \mathrm{~min}$ before $\mathrm{P}_{4}(2 \mathrm{mg} / \mathrm{mouse})$ injection and then sacrificed $24 \mathrm{~h}$ later.

\section{Preparation of uterine samples during early pregnancy} Uterine samples during early pregnancy were prepared as previously described [35]. Briefly, 8- to 10-week-old female mice were housed with proven fertile males for pregnancy. The next morning when the vaginal plug was found was considered as day 1 . Pregnant mice were sacrificed on various days of pregnancy, and their uteri were collected for real-time RT-PCR and/or immunofluorescence. IS in the morning $(0900 \mathrm{~h})$ of day 5 and 6 were visualized by intravenous injection $(0.1 \mathrm{ml} /$ mouse $)$ of Chicago sky blue 6B solution (1\% in saline, SigmaAldrich). The IS were demarcated by discrete blue bands along the uterus. IS on day 6 were collected and immediately frozen in liquid nitrogen for frozen section to perform histological analyses including immunofluorescence staining and alkaline phosphatase (ALP) activity assay.

To induce an experimentally-induced delayed implantation model in mice, pregnant ICR female mice were OVX at the morning of day 4 and given $\mathrm{P}_{4}(2 \mathrm{mg} / \mathrm{mouse})$ from day 5 to 7 as described previously [51]. To activate dormant blastocysts and initiate implantation, $\mathrm{P}_{4}$-primed delayed implanting pregnant mice were injected with $\mathrm{E}_{2}$ ( $25 \mathrm{ng} /$ mouse) on day 7 . Mice were sacrificed $24 \mathrm{~h}$ after the last hormone injection, and IS were visualized using Chicago sky blue 6B solution.

\section{RNA extraction, RT-PCR, and real-time RT-PCR}

The experiment was performed as previously described [35]. Briefly, uteri (3-5 mice per each group) were collected and immediately frozen in liquid nitrogen. Then, total RNA was extracted individually using Trizol Reagent (Ambion, USA) according to manufacturer's protocols. cDNA was synthesized from total RNA using M-MLV reverse transcriptase (Promega, USA) with random primers and oligo dT. Synthesized cDNA was utilized for PCR with specific primers at optimized cycles. Real-time RT-PCR was performed by monitoring realtime increases in the fluorescence of SYBR Green dye. Real-time RT-PCR was performed using the Realtime PCR detection system (Bio-Rad, USA) and $\mathrm{iQ}^{\mathrm{TM}} \mathrm{SYBR}^{\circledR}$ Green supermix (Bio-Rad). For comparison of transcript levels between samples, a standard curve of cycle thresholds for several serial dilutions of a cDNA sample was established and then used to calculate the relative abundance of each gene. Values were then normalized to the relative amounts of $r P L 7 \mathrm{cDNA}$. All PCR reactions were performed in duplicate.

\section{Immunofluorescence staining}

To determine the presence and cell-type specific localization of PLA2G10 after $\mathrm{P}_{4}$ treatment, and during the estrous cycle and early pregnancy, uteri were fixed in 4\% paraformaldehyde (PFA) and embedded in paraplast 
(Leica Biosystems, Germany). Uterine sections $(5 \mu \mathrm{m})$ were deparaffinized, rehydrated, and subjected to antigen retrieval in $0.01 \mathrm{M}$ sodium citrate buffer, $\mathrm{pH}$ 6.0, for $20 \mathrm{~min}$. For immunofluorescence staining of ARG2 (Arginase 2), a marker for decidualization, frozen sections $(13 \mu \mathrm{m})$ of IS on day 6 were fixed in 4\% PFA, washed in PBS, and permeabilized with $0.1 \%$ triton-X 100 in PBS. Non-specific staining was blocked using Protein Block Serum-Free (Dako, Denmark) for $1 \mathrm{~h}$. Then, sections were incubated overnight with primary rabbit-antiPLA2G10 antibody (1:100, Santa Cruz Biotechnology, USA) for PLA2G10 or primary rabbit-anti-ARG2 antibody (1:200, abcam, USA) for ARG2 at $4{ }^{\circ} \mathrm{C}$, washed in phosphate-buffered saline (PBS), and incubated with Alexa Fluor 488 goat-anti-rabbit secondary antibody (1:1000, Invitrogen Corp., USA) for $1 \mathrm{~h}$ at room temperature. Sections were washed in PBS, counterstained with propidium iodide (PI, Sigma-Aldrich) for $20 \mathrm{~min}$, and mounted for observation using a LSM880 confocal microscope (Carl Zeiss, Germany).

\section{Hematoxylin \& Eosin (H\&E) staining and ALP activity assay} H\&E staining and ALP activity assay were performed to evaluate gross histology of implanted embryos and decidualization in IS of the uterus with siPla2g10 on day 6 , respectively. Frozen sections $(13 \mu \mathrm{m})$ were fixed in $4 \%$ PFA, washed in PBS, and either stained with hematoxylin (Cancer Diagnostics, USA) and eosin (Richard Allan Scientific, USA) or incubated with a $100 \mathrm{mM}$ Tris $\mathrm{HCl}$ buffer ( $\mathrm{pH}$ 9.5) containing ALP substrate working solution (Vector Laboratories, SK-5400, USA). Slides were counterstained with fast red and mounted to observe ALP activity under light microscopy.

\section{Construction of expression and reporter vectors}

A proximal region $(-840$ to +65$)$ of Pla2g10 promoter (p) was amplified from mouse genomic DNA by PCR with Forward 1 (5'-GCT AGC GGT GGT TCC AAG GTT TCA CTC AG-3') and Reverse 1 (5'-CTC GAG GTC ACA GAG GTG GCC CAC AC-3') primers. The amplified Pla2g10(p) was cloned into pGL4.10 vector (Promega) and named pGL4.10/Pla2g10(p)-840/+65. The vector was independently mutated at four PREs, namely $-801 /-794,-356 /-349,-310 /-303$, and $-290 /-283$ in Pla2g10(p)-840/ + 65 using the EZ change ${ }^{\mathrm{TM}}$ Site-directed Mutagenesis Kit (Enzynomics, Inc., Korea). The four mutated PREs were named pGL4.10/Pla2g10(p)-801mt, pGL4.10/Pla2g10(p)-356mt, pGL4.10/Pla2g10(p)-310mt, and pGL4.10/Pla2g10(p)-290mt, respectively. PRA and PRB CDNAs were provided by Dr. J.W. Jeong (Michigan State University, MI, USA). The cDNAs were cloned into a
pcDNA3.1 NheI-XhoI site and named pcDNA3.1/PRA and pcDNA3.1/PRB, respectively.

\section{Transfection and luciferase assay}

Ishikawa cells, human endometrial adenocarcinoma cells, were plated in 12-well plates with DMEM/F12 and $10 \%$ charcoal-stripped (CS)-FBS $24 \mathrm{~h}$ before transfection. pcDNA3.1, pcDNA3.1/PRA, or pcDNA3.1/PRB expression vectors were co-transfected with pGL4.10/ Pla2g10(p)-840/ +65, pGL4.10/Pla2g10(p)-801mt, pGL4.10/Pla2g10(p)-356mt, pGL4.10/Pla2g10(p)-310mt, or pGL4.10/Pla2g10(p)-290mt vectors, and a pRL-null vector that was used as an internal control for normalization by GenePORTER ${ }^{\circledR} 3000$ Transfection Reagent (Genlantis, USA). The medium was replaced with DMEM/F12 and $2 \%$ CS-FBS with $1 \mu \mathrm{M} \mathrm{P}_{4}$ (Sigma-Aldrich) $4 \mathrm{~h}$ after transfection. Cells were harvested and analyzed for firefly and renilla luciferase activities using the Dual-Glo ${ }^{\text {TM }}$ Luciferase Assay System (Promega) $24 \mathrm{~h}$ after transfection. Luminescence was measured with Synergy $\mathrm{Mx}^{\mathrm{TM}}$ (Bio Tek, Inc., USA).

\section{In vivo RNA interference of $\mathrm{Pla2g} 10$ in mouse uterus}

Knock-down of Pla2g10 in mouse uterus was performed as previously described by Ruan et al. with some modifications [48]. Briefly, 100 pmol siPla2g10 (BIONEER Corp., Korea; 5'-GAA CAA AUG CCA AGA ACU U-3') or siNC (BIONEER Corp.) were combined with $5 \mu \mathrm{l}$ of lipofectamine 2000 in $10 \mu \mathrm{l}$ of Opti-MEM. The solutions were injected into each uterine horn at 18:00-20:00 $\mathrm{h}$ on day 3 for in vivo RNA interference of Pla2g10 in mouse uterus.

\section{Statistics}

All values represent the mean \pm standard deviation. The unpaired Student's $t$-test was used for statistical evaluation. A p-value of less than 0.05 was considered statistically significant.

\section{Acknowledgements \\ Not applicable.}

\section{Authors' Contributions}

HRK and HS conceived and designed the experiments in the manuscript. HKP and SHP performed the formal analysis. HKP, SHP, ML, GRK, MP, SCY, YSK and HJL performed the experiments and analyzed data. HKP, SHP, ML, GRK, MP, SCY, YSK and HJL performed the data visualization. HRK and HS supervised this study. HKP, SHP, HRK and HS wrote the original draft. HKP, SHP, HJL, HRK and HS reviewed and edited the manuscript. All authors read and approved the final manuscript.

\section{Funding}

This research was supported by Basic Science Research Program through the National Research Foundation of Korea (NRF) funded by the Ministry of Education (NRF-2019R1A6A1A03032888) and by the National Research Foundation of Korea (NRF) grant funded by the Korea government (MSIT) (Nos. NRF2020R1A2C2005012 and 2020R1C1C1008317). 


\section{Availability of data and materials}

All data generated or analyzed during this study are included in this published article.

\section{Ethics approval and consent to participate}

This study was approved by the Institution Review Board at CHA Bundang Medical Center, CHA University, before sample collection (IRB No 2011-01-001) and all women signed an informed consent form before participating in the study.

\section{Consent for publication}

The content of the manuscript has been approved by all the authors.

\section{Competing interests}

The authors declare that they have no competing interests.

\section{Author details}

${ }^{1}$ Department of Biomedical Science, CHA University, Gyeonggi-do, Seongnam-si 13488, Republic of Korea. ${ }^{2}$ Department of Veterinary Medicine, Konkuk University, Seoul 05029, Republic of Korea. ${ }^{3}$ Present Address: Division of Endocrinology and Metabolism, Department of Internal Medicine, Collage of Medicine, Gil Medical Center, Gachon University, Incheon 21565, Republic of Korea.

Received: 6 July 2020 Accepted: 9 November 2020

Published online: 19 November 2020

\section{References}

1. Song H, Lim H, Paria B, Matsumoto H, Swift L, Morrow J, et al. Cytosolic phospholipase A2alpha is crucial [correction of A2alpha deficiency is crucial] for 'on-time' embryo implantation that directs subsequent development. Development. 2002;129(12):2879-89.

2. Brown N, Morrow JD, Slaughter JC, Paria BC, Reese J. Restoration of on-time embryo implantation corrects the timing of parturition in cytosolic phospholipase A2 group IVA deficient mice. Biol Reprod. 2009:81(6):1131-8.

3. Niringiyumukiza JD, Cai H, Xiang W. Prostaglandin E2 involvement in mammalian female fertility: ovulation, fertilization, embryo development and early implantation. Reprod Biol Endocrin. 2018;16(1):43.

4. Murakami M, Yamamoto K, Miki Y, Murase R, Sato H, Taketomi Y. The roles of the secreted phospholipase A2 gene family in immunology. Adv Immunol. 2016:132:91-134.

5. Choi Y, Kim H-R, Lim EJ, Park M, Yoon JA, Kim YS, et al. Integrative analyses of uterine transcriptome and microRNAome reveal compromised LIF-STAT3 signaling and progesterone response in the endometrium of patients with recurrent/repeated implantation failure (RIF). PLOS ONE. 2016;11(6):e0157696.

6. Wang H, Dey SK. Roadmap to embryo implantation: clues from mouse models. Nat Rev Genet. 2006;7(3):185-99.

7. Lim HJ, Wang H. Uterine disorders and pregnancy complications: insights from mouse models. J Clin Invest. 2010;120(4):1004-15.

8. Wu SP, Li R, DeMayo FJ. Progesterone receptor regulation of uterine adaptation for pregnancy. Trends Endocrin Met. 2018;29(7):481-91.

9. Patel B, Elguero S, Thakore S, Dahoud W, Bedaiwy M, Mesiano S. Role of nuclear progesterone receptor isoforms in uterine pathophysiology. Hum Reprod Update. 2015;21(2):155-73.

10. Marquardt RM, Kim TH, Shin JH, Jeong JW. Progesterone and estrogen signaling in the endometrium: what goes wrong in endometriosis? Int J Mol Sci. 2019;20(15):3822

11. Cha J, Sun X, Dey SK. Mechanisms of implantation: strategies for successful pregnancy. Nat Med. 2012;18(12):1754-67.

12. Gnainsky Y, Dekel N, Granot I. Implantation: mutual activity of sex steroid hormones and the immune system guarantee the maternal-embryo interaction. Semin Reprod Med. 2014;32(5):337-45.

13. Fujiwara $H$, Ono M, Sato $Y$, Imakawa $K$, lizuka T, Kagami $K$, et al. Promoting roles of embryonic signals in embryo implantation and placentation in cooperation with endocrine and immune systems. Int J Mol Sci. 2020;21(5):1885
14. Arck P, Hansen PJ, Mulac Jericevic B, Piccinni MP Szekeres-Bartho J. Progesterone during pregnancy: endocrine-immune cross talk in mammalian species and the role of stress. Am J Reprod Immunol. 2007;58(3):268-79.

15. Solano ME, Arck PC. Steroids, pregnancy and fetal development. Front Immunol. 2019;10:3017

16. Piette PC. The pharmacodynamics and safety of progesterone. Best Pract Res. 2020;25;S1521-6934(20)30092-4.

17. Wetendorf M, DeMayo FJ. Progesterone receptor signaling in the initiation of pregnancy and preservation of a healthy uterus. Int J Dev Biol. 2014;58:95.

18. Das S, Chakraborty I, Paria B, Wang X, Plowman G, Dey S. Amphiregulin is an implantation-specific and progesterone-regulated gene in the mouse uterus. Mol Endocrinol. 1995:9(6):691-705.

19. Matsumoto H, Zhao X, Das SK, Hogan BL, Dey SK. Indian hedgehog as a progesterone-responsive factor mediating epithelial-mesenchymal interactions in the mouse uterus. Dev Biol. 2002;245(2):280-90.

20. Zhu L-J, Cullinan-Bove K, Polihronis M, Bagchi MK, Bagchi IC. Calcitonin is a progesterone-regulated marker that forecasts the receptive state of endometrium during implantation. Endocrinology. 1998;139(9):3923-34.

21. Rubel CA, Wu SP, Lin L, Wang T, Lanz RB, Li X, et al. A Gata2-dependent transcription network regulates uterine progesterone responsiveness and endometrial function. Cell Rep. 2016;17(5):1414-25.

22. Wang X, Li X, Wang T, Wu SP, Jeong JW, Kim TH, et al. SOX17 regulates uterine epithelial-stromal cross-talk acting via a distal enhancer upstream of Ihh. Nat Commun. 2018;9(1):4421.

23. Young IR, Renfree MB, Mesiano S, Shaw G, Jenkin G, Smith R. The comparative physiology of parturition in mammals: hormones and parturition in mammals. In: Hormones and reproduction of vertebrates. Elsevier: Amsterdam; 2011. p. 95-116.

24. Milligan SR, Finn CA. Minimal progesterone support required for the maintenance of pregnancy in mice. Hum Reprod. 1997;12(3):602-7.

25. Rubel CA, Lanz RB, Kommagani R, Franco HL, Lydon JP, DeMayo FJ. Research resource: genome-wide profiling of progesterone receptor binding in the mouse uterus. Mol Endocrinol. 2012;26(8):1428-42.

26. Murakami M, Lambeau G. Emerging roles of secreted phospholipase A(2) enzymes: an update. Biochimie. 2013;95(1):43-50.

27. Wang $\mathrm{H}$, Dey SK. Lipid signaling in embryo implantation. Prostaglandins. 2005;77(1-4):84-102.

28. Ye X, Hama K, Contos JJ, Anliker B, Inoue A, Skinner MK, et al. LPA3mediated lysophosphatidic acid signalling in embryo implantation and spacing. Nature. 2005:435(7038):104-8.

29. Hama K, Aoki J, Inoue A, Endo T, Amano T, Motoki R, et al. Embryo spacing and implantation timing are differentially regulated by LPA3-mediated lysophosphatidic acid signaling in mice. Biol Reprod. 2007;77(6):954-9.

30. Ye X, Diao H, Chun J. 11-deoxy prostaglandin F2a, a thromboxane A2 receptor agonist, partially alleviates embryo crowding in Lpar3 (-/-) females. Fertil Steril. 2012;97(3):757-63.

31. Nahed RA, Martinez G, Escoffier J, Yassine S, Karaouzène T, Hograindleur J-P, et al. Progesterone-induced acrosome exocytosis requires sequential involvement of calcium-independent phospholipase A2 $\beta$ (iPLA2 $\beta$ ) and group X secreted phospholipase A2 (sPLA2). J Biol Chem. 2016:291(6):3076-89

32. Lim HJ, Dey SK. HB-EGF: a unique mediator of embryo-uterine interactions during implantation. Exp Cell Res. 2009;315(4):619-26.

33. Green CJ, Fraser ST, Day ML. Insulin-like growth factor 1 increases apical fibronectin in blastocysts to increase blastocyst attachment to endometrial epithelial cells in vitro. Hum Reprod. 2015:30(2):284-98.

34. Rosario GX, Stewart CL. The multifaceted actions of leukaemia inhibitory factor in mediating uterine receptivity and embryo implantation. Am J Reprod Immunol. 2016;75(3):246-55.

35. Kim HR, Kim YS, Yoon JA, Yang SC, Park M, Seol DW, et al. Estrogen induces EGR1 to fine-tune its actions on uterine epithelium by controlling PR signaling for successful embryo implantation. FASEB J. 2018;32(3):1184-95

36. Franco HL, Jeong JW, Tsai SY, Lydon JP, DeMayo FJ. In vivo analysis of progesterone receptor action in the uterus during embryo implantation. Semin Cell Dev Biol. 2008;19(2):178-86.

37. Large MJ, DeMayo FJ. The regulation of embryo implantation and endometrial decidualization by progesterone receptor signaling. Mol Cell Endocrinol. 2012;358(2):155-65. 
38. Xie H, Wang H, Tranguch S, Iwamoto R, Mekada E, Demayo FJ, et al. Maternal heparin-binding-EGF deficiency limits pregnancy success in mice. Proc Natl Acad Sci USA. 2007;104(46):18315-20.

39. Achache $\mathrm{H}$, Revel A. Endometrial receptivity markers, the journey to successful embryo implantation. Hum Reprod Update. 2006;12(6):731-46.

40. Cavagna M, Mantese JC. Biomarkers of endometrial receptivity-a review. Placenta. 2003:24(Suppl B):S39-47.

41. Rubel CA, Franco HL, Jeong J-W, Lydon JP, DeMayo FJ. GATA2 is expressed at critical times in the mouse uterus during pregnancy. Gene Expr Patterns. 2012;12(5-6):196-203.

42. Simon L, Spiewak KA, Ekman GC, Kim J, Lydon JP, Bagchi MK, et al. Stromal progesterone receptors mediate induction of Indian Hedgehog $(\mathrm{IHH})$ in uterine epithelium and its downstream targets in uterine stroma. Endocrinology. 2009;150(8):3871-6.

43. Franco HL, Rubel CA, Large MJ, Wetendorf M, Fernandez-Valdivia R, Jeong $J W$, et al. Epithelial progesterone receptor exhibits pleiotropic roles in uterine development and function. FASEB J. 2012;26(3):1218-27.

44. Tan J, Paria BC, Dey SK, Das SK. Differential uterine expression of estrogen and progesterone receptors correlates with uterine preparation for implantation and decidualization in the mouse. Endocrinology. 1999;140(11):5310-21

45. Croy BA, Yamada AT, DeMayo FJ, Adamson SL. The guide to investigation of mouse pregnancy. New York: Academic Press; 2013.

46. Wetendorf M, Wu S-P, Wang X, Creighton CJ, Wang T, Lanz RB, et al. Decreased epithelial progesterone receptor $A$ at the window of receptivity is required for preparation of the endometrium for embryo attachment. Biol Reprod. 2017;96(2):313-26.

47. Kurita T, Lee KJ, Cooke PS, Taylor JA, Lubahn DB, Cunha GR. Paracrine regulation of epithelial progesterone receptor by estradiol in the mouse female reproductive tract. Biol Reprod. 2000;62(4):821-30.

48. Ruan YC, Guo JH, Liu X, Zhang R, Tsang LL, Dong JD, et al. Activation of the epithelial $\mathrm{Na}+$ channel triggers prostaglandin $\mathrm{E}(2)$ release and production required for embryo implantation. Nat Med. 2012;18(7):1112-7.

49. Chen JJ, Xiao ZJ, Meng X, Wang Y, Yu MK, Huang WQ, et al. MRP4 sustains Wnt/beta-catenin signaling for pregnancy, endometriosis and endometrial cancer. Theranostics. 2019;9(17):5049-64.

50. Zhang D, Yang Y, Liang C, Liu J, Wang H, Liu S, et al. poFUT1 promotes uterine angiogenesis and vascular remodeling via enhancing the O-fucosylation on uPA. Cell Death Dis. 2019;10(10):775.

51. Lee JE, Oh HA, Song H, Jun JH, Roh CR, Xie H, et al. Autophagy regulates embryonic survival during delayed implantation. Endocrinology. 2011;152(5):2067-75.

\section{Publisher's Note}

Springer Nature remains neutral with regard to jurisdictional claims in published maps and institutional affiliations.
Ready to submit your research? Choose BMC and benefit from:

- fast, convenient online submission

- thorough peer review by experienced researchers in your field

- rapid publication on acceptance

- support for research data, including large and complex data types

- gold Open Access which fosters wider collaboration and increased citations

- maximum visibility for your research: over 100M website views per year

At BMC, research is always in progress.

Learn more biomedcentral.com/submissions 